\title{
ESTÁGIO SUPERVISIONADO E PRÁTICAS DE ORALIDADE, LEITURA E ESCRITA NO ENSINO FUNDAMENTAL
}

\author{
Idméa Semeghini-Siqueira* \\ Gema Galgani BezerRa* \\ TATIANA GuAZZELli ${ }^{* * *}$
}

\begin{abstract}
RESUMO: Este artigo propóe-se a discorrer sobre o contexto de realização de um projeto de comunicação a distância entre alunos do ensino fundamental $(\mathrm{EF})$ mediada por estagiários e professores. Trata-se de uma modalidade de estágio supervisionado proposto aos alunos de Pedagogia e de Licenciatura na disciplina "Metodologia do Ensino de Português". O objetivo da proposta é motivar o aluno do EF a se apropriar de seu papel de sujeito na interlocução, descobrindo o prazer de ler e escrever e a importância de estar bem instrumentalizado para se comunicar. O projeto consiste numa proposta geral que tem por finalidade desencadear a construção de um projeto específico pelo estagiário, com a colaboração do professor do EF. Envolve, para tanto, um trabalho intenso com a linguagem verbal e com as linguagens não verbais. Ao mesmo tempo, viabiliza-se o intercâmbio entre universidade e escola e caminhos são apontados para a formação inicial e contínua do professor de língua materna.
\end{abstract}

Palavras-chave: Estágio supervisionado. Interação leitura-escrita. Ensino de língua materna. Formação de professores.

\footnotetext{
* Doutora em Linguística e professora da Faculdade de Educação da Universidade de São Paulo (USP).E-mail: isemeghi@usp.br

** Doutoranda em Educação na Faculdade de Educação da UsP e professora titular na rede municipal de Ensino de São Paulo.E-mail: gegal@usp.br

*** Mestre em Educação e professora efetiva Pebi da rede estadual de Ensino de São Paulo. E-mail: taguazze@hotmail.com
} 
Estágio supervisionado e práticas de oralidade, leitura e escrita no ensino fundamental

SUPERVISED TRAINING COURSE AND READING, WRITING AND ORAL COMMUNICATION PRACTICES IN ELEMENTARY AND MIDDLE SCHOOLS

ABSTRACT: This paper discusses the context of a distance communication project involving Brazilian elementary and middle schools (EMS) students mediated by trainees and teachers. This supervised training course for students of the Pedagogy and the Pre-service Teacher Education Programs is part of the "Portuguese Teaching Methodology" course. It aims to motivate EMs students to take on their role as subjects in interlocutions, discovering the pleasure of both writing and reading, and the importance of being well equipped to achieve successful communication. The training course modality consists of guidelines that help trainees to build specific projects in cooperation with EMS teachers, involving intense work with verbal and non-verbal languages. The project development allows both exchanges between university and school, and the pre-service and continuing education of mother-tongue teachers.

Key words: Supervised training course. Reading-writing interaction. Mother-tongue teaching. Teacher education.

$\mathcal{E}$

ste artigo propõe-se a discorrer sobre dois grandes desafios que estão norteando a formação do professor de língua materna. $\mathrm{O}$ primeiro é o de viabilizar o intercâmbio entre universidade e esco$l a$, por meio do estágio supervisionado realizado por alunos dos cursos de Licenciatura e de Pedagogia, para que as trocas possam apontar caminhos a serem trilhados na formação inicial e contínua do professor de língua materna. O segundo é propor atividades que visem ao desenvolvimento da oralidade, da leitura e da produção escrita de forma prazerosa e, consequentemente, propiciar o avanço dos alunos com dificuldades de aprendizagem em leitura e escrita.

O projeto CADIS - comunicação a distância entre alunos do ensino fundamental mediada por estagiários e professores - envolve um trabalho intenso com a linguagem verbal (modalidades oral e escrita) e com as linguagens não verbais (artes visuais, audiovisuais, música) e é proposto aos alunos da Faculdade de Educação da Universidade de São Paulo (USP) todos os anos, desde 1999, na disciplina Metodologia do Ensino de Português. Cabe ressaltar que se trata de um macroprojeto, ou seja, de uma proposta preliminar com o objetivo de alavancar a 
construção de projetos específicos por estagiários em colaboração com o professor do ensino fundamental (EF).

Trataremos aqui de explicitar o projeto de pesquisa e os resultados mais significativos que nos permitiram chegar a algumas conclusões rumo à construção de propostas para aulas de Língua Portuguesa no século XXI. Para tanto, abordaremos o problema que suscitou o projeto; apresentaremos os procedimentos metodológicos que envolvem a proposta geral, o projeto específico e sua execução; ressaltaremos a importância da constituição de grupos heterogêneos/complementares como estratégia imprescindível na implementação do projeto CADIS e discutiremos os pressupostos teóricos da concepção interacional e sócio-discursiva de linguagem que estão subsidiando a formação dos professores que atuam no projeto. Farão parte deste texto, também, dois relatos de experiência, uma vez que se considera ser de fundamental relevância dar voz àqueles que participaram do projeto: os estagiários. Além desses relatos, apresentaremos uma análise dos projetos desenvolvidos em 2008 e uma incursão pelos dez anos do CADIS.

\section{Do problema à busca de soluções}

Em investigações e avaliações nacionais e internacionais recentes, verificou-se que um número expressivo de alunos de escolas públicas, após oito anos de escolarização, carrega sequelas do fracasso escolar, apresentando graus restritos de letramento. Desse modo, vivem em desconforto constante ao utilizar a língua materna para ler ou escrever, uma vez que demonstram insuficientes habilidades no uso da modalidade escrita da língua, em vista do que seria aceitável para sua atuação em um mundo globalizado.

A linguagem exerce um papel decisivo na construção do conhecimento de crianças e jovens, de modo a funcionar como eixo articulador que permeia a interação entre todos os atores do processo educativo e entre todas as disciplinas na escola. Além disso, todo texto oral ou escrito se organiza dentro de um determinado gênero discursivo, que pode ser considerado como um instrumento específico do qual os falantes se utilizam para viabilizar o processo de interação verbal (Bronckart, 1997; Schneuwly \& Dolz, 2004). Há uma variedade de gêneros discursivos que podem ser trabalhados na escola e é importante 
Estágio supervisionado e práticas de oralidade, leitura e escrita no ensino fundamental

criar situações para que os alunos utilizem essa diversidade textual para desenvolver habilidades de leitura e escrita.

Esta ênfase se justifica porque, enquanto não forem efetivadas as condiçôes para que o aluno se torne um leitor eficiente, assegurandolhe um desempenho satisfatório na modalidade escrita da língua materna, seu rendimento em outras disciplinas será, provavelmente, deficitário. A possibilidade de compreensão de um texto, por exemplo, que expresse um problema matemático está, em princípio, na dependência da capacidade de ler do educando.

Nesse sentido, uma das metas deste projeto é propor e viabilizar a realização de atividades que possam incluir todos os alunos, em particular, aqueles com graus restritos de letramento, uma vez que somente uma escola inclusiva pode ser considerada efetivamente democrática, pois abre oportunidades educacionais adequadas a todos os alunos.

Destacamos que o termo "inclusão" está sendo utilizado de modo mais abrangente, como ocorre em muitos países. Não se refere, portanto, apenas à inserção dos alunos portadores de necessidades educacionais específicas nas classes comuns, mas também das crianças cujos pais pertencem a classes sociais e econômicas desfavorecidas, crianças com quaisquer dificuldades de aprendizagem, apresentando ou não algum tipo de deficiência, e mesmo crianças muito bem sucedidas, como as superdotadas.

Ao focalizar a inclusão/integração dos alunos com dificuldades de aprendizagem, espera-se minimizar o problema do "fracasso escolar", pelo trabalho com grupos heterogêneos/comple-mentares e práticas de oralidade, leitura e escrita significativas.

Procedimentos metodológicos: proposta geral, projeto específico e execução

O projeto CADIS consiste numa proposta geral, que tem por finalidade desencadear a construção de um projeto específico pelo estagiário, com a colaboração do professor, no intuito de promover a comunicação a distância entre grupos de alunos do EF. Assim, os projetos elaborados pelos estagiários constituem propostas para trabalhar com grupos heterogêneos de alunos do EF de diferentes escolas, os quais passam a ter a oportunidade de se corresponderem, contando com a mediação do 
professor e do estagiário. Esse trabalho viabiliza o uso da linguagem verbal (oral e escrita) em um contexto específico, assim como das linguagens não verbais (desenhos, fotos e músicas). Ao apresentar o projeto para os grupos de alunos do EF, o professor e o estagiário também permitem que eles tenham um percurso próprio no decorrer de sua execução. A imaginação, a curiosidade, as vivências e os interesses dos alunos constituem a mola propulsora das interações, ainda que seja fundamental estabelecer regras de funcionamento do grupo, negociadas por todos os participantes (Biarnès, 1999).

A correspondência pode ser realizada por um ou vários meios (correio, fax, internet ou outros), mas, no projeto CADIs, a opção mais viável para manter o interesse dos alunos é o transporte das produçóes escritas, pelo próprio estagiário, de um local para outro. É oportuno explicitar que, para a troca de correspondências, os estagiários encontravam-se na Universidade.

A proposta feita aos estagiários no âmbito do CADIs permite-lhes apresentar um projeto específico em parceria ou não com outro estagiário, porém em duas escolas ou espaços não escolares diferentes. O professor e o estagiário atuam como mediadores na interação dialógica entre alunos do EF, explorando a diversidade de gêneros discursivos existentes nas práticas sociais, sejam literários e/ou pragmáticos, envolvendo vivências artísticas e estéticas. São lançados desafios aos alunos, com o intuito de dar continuidade ao processo dinâmico de letramento, possibilitando um uso mais eficaz da língua ao falar, escutar, ler e escrever (Freinet, 1967).

O que está subjacente a essa proposta? A intenção de motivar o aluno do EF para que ele se aproprie de seu papel de sujeito na interação, descobrindo o prazer de ler e de escrever e a importância de estar bem instrumentalizado para se comunicar. Para que isto ocorra no EF, não há "conteúdos específicos" como, por exemplo, em Ciências ou em História. No ensino de língua materna para o EF, a prioridade é o professor possibilitar aos alunos uma imersão na linguagem verbal: oral e escrita (Macedo \& Semeghini-Siqueira, 2000).

No Quadro 1, mais adiante, a variedade de títulos dos projetos específicos, além dos dois relatos de experiência, pode propiciar ao leitor uma noção de como ocorreu a prática pedagógica desencadeada pelo projeto CADIS. 
Estágio supervisionado e práticas de oralidade, leitura e escrita no ensino fundamental

Grupos heterogêneos/complementares: uma estratégia imprescindível no projeto CADIS

Numa escola de qualidade para todos, o trabalho em grupos formados por alunos em diferentes estágios de conhecimento pode funcionar como chave para acabar com o estigma dos "fracassados", portadores de necessidades educacionais específicas ou não. Para implantar o projeto CADIS no espaço educacional selecionado pelo estagiário, é imprescindível a formação estratégica de grupos heterogêneos/complementares, de maneira que alunos com dificuldades de aprendizagem em leitura e escrita possam interagir com colegas que apresentem um ótimo rendimento nestas atividades e com outros que já começaram a avançar. Estes grupos são formados com o auxílio do professor da classe regular, a partir de uma avaliação diagnóstica da produção escrita dos alunos. Como a interação é feita grupo a grupo, os estagiários formam o mesmo número de grupos em cada escola.

Em relação aos alunos com dificuldades de aprendizagem, a mediação propiciada pelos colegas que têm melhor desempenho e pelo professor/estagiário possibilita que esses alunos avancem mais rapidamente. Um dos conceitos-chave de Vigotski (1984) - a zona de desenvolvimento proximal - está permeando os procedimentos adotados neste projeto. No livro A formação social da mente (1984, p. 98), o autor esclarece que "(...) aquilo que é zona de desenvolvimento proximal hoje será o nível do desenvolvimento real amanhã, ou seja, aquilo que uma criança pode fazer com assistência hoje, ela será capaz de fazer sozinha amanhã". Para isso ocorrer, além de trabalhar a partir daquilo que o aluno já faz, considerando seus conhecimentos prévios, deve-se recorrer à interação com o outro, que o auxilia e o aproxima daquilo que ele poderá vir a realizar. Daí a importância do trabalho em grupo. A aprendizagem estimula um conjunto de processos internos que, permeados pelas interações com os outros, se convertem em aquisiçôes particulares e internas da criança (Wertsch \& Smolka, 1994).

Ao acolher os alunos com dificuldades de aprendizagem nos grupos heterogêneos, compartilhamos da luta pela educação de qualidade para todos, a exemplo de experiências vividas em outros países que visam dar conta da heterogeneidade na sala de aula (Meirieu, 1995; Lahire, 1995). 
Formação do professor de linguagem no âmbito do projeto CADIS: quadro teórico

Com relação aos restritos graus de letramento dos adolescentes, após oito anos de escolarização, há consenso quanto à complexidade do problema, pois uma reflexão sobre esses graus envolve fatores de âmbito cultural, cognitivo-afetivo, linguístico-discursivo, socioeconômico, de políticas públicas e de práticas educativas. Neste texto, abordamos as práticas educativas.

Certamente, compete à universidade reinventar a formação dos professores de língua materna, contribuindo para que eles possam, por sua vez, reinventar as práticas educativas. Entretanto, em SemeghiniSiqueira (2000), foi demonstrado que a formação universitária, tanto do professor que trabalha no ciclo I quanto daquele que atua no ciclo II, não tem produzido alteraçôes concretas nas práticas pedagógicas, ou seja, a maioria dos docentes "continua atuando como seus antigos professores".

Vale lembrar que, se em determinada época o mote era "o fracasso do aluno", depois "o fracasso da escola" (ou do professor do EF), pode-se agora apontar numa outra direção: "o fracasso da formação universitária". É premente, pois, que toda a comunidade acadêmica envide esforços para solucionar esse impasse.

Assim sendo, nos perguntamos como deveria ser a formação de um professor de Língua Portuguesa para atuar nesse novo contexto. De que requisitos este professor precisa estar munido para enfrentar, ao mesmo tempo, a diversidade de alunos e o quadro de fracasso escolar construído ao longo das últimas décadas? Na senda de SemeghiniSiqueira (1998), discutiremos um tópico que envolve teoria da linguagem e práticas educativas, alicerçado pelos pressupostos teóricos da concepção interacional e sócio-discursiva de linguagem de Bakhtin, que estão subsidiando a formação dos professores que atuam no projeto CADIs.

$\mathrm{Na}$ concepção de Bakhtin, não há uma dissociação entre o contexto social e o desenvolvimento da linguagem. A linguagem é, na verdade, um fenômeno social e histórico, ou seja, ela é produzida num contexto social real. Portanto, para se compreender determinado enunciado, deve-se relacioná-lo a um contexto específico e concreto e não se limitar apenas ao produto apresentado. Mais do que isso, a compreensão é um processo em que há um confronto entre as enunciações do 
Estágio supervisionado e práticas de oralidade, leitura e escrita no ensino fundamental

falante e as enunciações do ouvinte. Nesta interação, é a negociação que possibilita o diálogo entre interlocutores (Bakhtin, 1981 e 1992).

O dialogismo é a condição para haver um sentido no discurso, uma vez que este não é individual, ocorrendo, pelo menos, entre dois interlocutores ou como um diálogo entre discursos. Bakhtin define o texto como um "tecido de muitas vozes" ou de muitos discursos. Segundo este autor, o discurso é dialógico e polifônico. Dialógico porque se concebe num espaço de interação com o outro e se constrói por meio dessa mesma interação, de acordo com os interesses do locutor e das imagens que este faz do interlocutor ou supõe que este faz dele; e polifônico porque, apesar de proferido por um sujeito específico, é perpassado por outras vozes, outros discursos que o precederam. Essa noção de concepção dialógica da linguagem tem importância dentro do perfil do professor de língua materna, porque ela permite ao educador compreender que não há leitura única, há sempre reconstrução.

Para Bakhtin (1981, p. 123), "A interação verbal constitui a realidade fundamental da língua”. A realização de atividades que privilegiem a interação verbal está distante da concepção de língua como objeto parcelável, que pode ser dividido em "partes" das mais simples às mais complexas. Na interação verbal, a língua "existe" como um todo orgânico.

Ressaltamos, também, que a interlocução com o outro ocorre por meio da linguagem verbal e não verbal. Como continuar ignorando a presença da linguagem não verbal, incrustada no uso da língua, tanto oral quanto escrita? Quando são realizadas atividades em grupo na sala de aula, há que se lembrar de que, nesta interlocução, ocorrem gestos, movimentos, olhares, entonaçóes, carregados de significados. $\mathrm{Na}$ escrita, os diferentes tipos de letras utilizados pelos alunos, a disposição do texto na folha, muitas vezes acompanhada por desenhos, atestam a inserção do não verbal no verbal. A interlocução com o outro se dá, portanto, por meio da linguagem verbal e não verbal. Assim, a aquisição e o desenvolvimento da modalidade escrita da língua necessitam ser pensados em termos de uma complexa e multifacetada interação, tendo como ponto de apoio uma concepção interacional e sócio-discursiva da linguagem.

O exercício dessa prática discursiva, viabilizada pelo CADIS, permite que cada aluno se posicione como falante, leitor e escritor e, portanto, 
protagonista do processo de construção do conhecimento numa perspectiva sócio-histórica (Smolka, 1988). A escrita atua neste processo como meio de expressão, comunicação e organização do pensamento, num movimento de construir, atribuir e compartilhar significados.

Como lembra Bakhtin (1981), a interlocução aparece na relação dialógica no espaço em que a palavra do outro passa a fazer parte do meu discurso. Tendo em vista a correspondência, por meio de cartas, o autor ressalta que: "É própria da carta uma sensação do interlocutor, do destinatário a quem ela visa. Como a réplica do diálogo, a carta se destina a um ser determinado, leva em conta as suas possíveis reações, sua possível resposta” (p. 123).

Esses pressupostos teóricos referentes à concepção interacional e sócio-discursiva da linguagem, que norteiam o projeto CADIs, estão subsidiando não só a formação inicial dos estagiários, mas também a formação contínua dos professores. As experiências com este projeto demonstraram que os professores do $\mathrm{EF}$, muitas vezes, repensam sua prática quando convidados pelos estagiários a dialogar, tendo em vista uma reconstrução de conhecimentos educacionais. Um dos objetivos do projeto implica a participação do professor da classe envolvida na elaboração das atividades propostas, tomando-se o cuidado de considerar aquelas que ele avalia, até então, como eficazes no ensino de língua materna. Ao mesmo tempo, o estagiário proporciona novas situações de aprendizagem que apontam outros caminhos para este profissional. Alguns professores passam a acreditar num ensino mais prazeroso, à medida que vivenciam a experiência relacionada ao movimento de ressignificar as aulas de Língua Portuguesa pelo encontro com os interlocutores reais.

Verifica-se, portanto, como decorrência do projeto CADIS, uma interferência na formação contínua de professores do EF. Nesse sentido, ao discutir a questão da formação contínua, Nóvoa (1992) cita o triplo movimento sugerido por Donald Schön: conhecimento na ação, reflexão na ação e reflexão sobre a ação e sobre a reflexão na ação. A prática seria a fornecedora de elementos para uma reflexão sobre ela mesma, podendo, a partir dessa reflexão, modificá-la. O professor seria um aprendiz reflexivo perante sua prática, pois, para Schön (1988, p. 83):

(...) é possível olhar retrospectivamente e refletir sobre a reflexão-naação. Após a aula, o professor pode pensar no que aconteceu, no que observou, no significado que lhe deu e na eventual adoção de outros 
sentidos. Refletir sobre a reflexão-na-ação é uma ação, uma observação e uma descrição, que exige o uso de palavras.

Nos relatos a seguir, pode-se notar como o projeto CADIS abre espaço para que as aulas de língua materna tenham um novo significado para os alunos, ao proporcionar, na interação com o outro, um caminho para a escola que queremos, ao mesmo tempo em que atua na formação inicial e contínua de professores.

\section{Relato de experiência: o projeto CADIS na Pedagogia}

O projeto específico "Comunicação a distância entre alunos da $3^{\text {a }}$ série do ensino fundamental: a busca pelo significado nas aulas de Língua Portuguesa” foi desenvolvido pelas alunas Maria Carolina Nogueira Dias e Tatiana Guazzelli, do $3^{\circ}$ ano de Pedagogia. A primeira realizou o estágio numa escola estadual localizada em Santo André. A segunda escolheu uma escola estadual situada no município de Osasco, na Grande São Paulo.

O fato de haver um motivo, a correspondência, para alunos usarem a língua constituiu um dado novo para as aulas das duas turmas. Foram propostas atividades, por meio das quais os alunos sentiram necessidade de se envolver com as diferentes formas de expressão, verbal e/ou não verbal. $\mathrm{O}$ contato com alunos de outra cidade, de mesma faixa etária, ocasionou curiosidade e despertou interesse.

Foram vivenciadas duas situações marcantes. A professora de Santo André "vestiu a camisa" do projeto, comunicou sua experiência aos colegas da escola e outras professoras começaram a desenvolver atividades semelhantes, tendo como foco a correspondência. $\mathrm{O}$ trabalho realizado nesta $3^{a}$ série ancorou-se em um projeto que a professora vinha desenvolvendo sobre a arte dos grandes pintores. Em Osasco, a classe se envolveu com o projeto, mas a professora não. Os alunos queriam conhecer Santo André, conhecer os novos amigos. A professora saía da sala enquanto o projeto era desenvolvido com as crianças. Foi estabelecida uma listagem de atividades que poderiam ser realizadas. Eles produziam o material e uma estagiária entregava para a outra. Ao final, cada grupo produziu um livro e um cartão de Natal com fotos. Alguns grupos já se sentiam íntimos e trocaram endereços. Não sabemos se a correspondência continuou após o término do projeto. 
Esta experiência demonstrou que atividades lúdicas e inusitadas (seja pelo material ou pela própria atividade) impulsionam os alunos a redescobrirem que escrevemos e lemos não porque a professora "manda fazer a cópia e/ou a lição", mas porque vivemos numa sociedade letrada e existe sempre o Outro. Eis o objetivo a ser alcançado: o falar, o ouvir, o ler e o escrever adquirem significado nas aulas de língua materna.

\section{Relato de experiência: o projeto CADIS na Licenciatura}

Em estágio realizado no curso de Licenciatura da Faculdade de Educação da USP, a dupla formada pelos estagiários Eduardo Passos e Gema Galgani Rodrigues Bezerra idealizou e implementou o projeto específico intitulado "Pontentomaquia: a guerra das superpotências", viabilizando a correspondência entre $7^{\mathrm{a}}$ e $6^{\mathrm{a}}$ séries de duas escolas, uma localizada no município de Arujá e a outra, em São Paulo.

Como o próprio título indicia, as atividades desenvolvidas em função do projeto contemplaram uma interação lúdica entre grupos de alunos, que passaram a "competir" no intuito de vencerem os desafios propostos pelos estagiários, com a colaboração das professoras das turmas. O estagiário Eduardo Passos produziu um conto especialmente para o projeto, que funcionou como uma espécie de mote introdutório às atividades, permeando todos os desafios do jogo, chamados de "combates".

Desse modo, o espírito de competição entre os grupos "inimigos" de uma mesma turma e de cooperação entre os grupos "aliados" das diferentes escolas impulsionou um engajamento real dos alunos nas atividades propostas, favorecendo a introdução de diversos gêneros discursivos na interação. Foi possível verificar, portanto, como são relevantes atividades que motivem o aluno a ler, escrever e interagir de modo significativo, possibilitando que avance no domínio da oralidade, da leitura, da escrita e das linguagens não verbais.

Análise de projetos específicos desenvolvidos em 2008

Na disciplina Metodologia do Ensino de Português (MElp) de 2008, quinze projetos específicos foram apresentados, por duplas de estagiários, no âmbito do CADIS. Embora houvesse outra modalidade de estágio, eles consideraram a proposta instigante e conseguiram que as 
Estágio supervisionado e práticas de oralidade, leitura e escrita no ensino fundamental

professoras das classes aceitassem abrir espaço/tempo em suas aulas. No quadro a seguir, apresentamos os títulos dos projetos específicos.

\section{Quadro 1}

(Projetos específicos no âmbito do CADIS em 2008)

\begin{tabular}{|c|c|}
\hline $\begin{array}{l}\text { No } \\
\text { Projetos }\end{array}$ & Projeto específico \\
\hline 01 & $\begin{array}{l}\text { Música: alimentando a alma e a escrita } \\
\text { (O ato e o resultado) }\end{array}$ \\
\hline 02 & Promovendo a troca de cartas entre leitor e revista \\
\hline 03 & Cartas seladas \\
\hline 04 & $\begin{array}{l}\text { Posso dizer com minhas palavras? } \\
\text { O despertar da leitura e da escrita em alunos do EF }\end{array}$ \\
\hline 05 & Conhecendo e revelando quem sou eu \\
\hline 06 & A magia na redescoberta da escrita por meio da ludicidade \\
\hline 07 & $\begin{array}{l}\text { Comunicação a distância: um atalho para o aprendizado sob o } \\
\text { eixo da informação }\end{array}$ \\
\hline 08 & Curiosidades de cá e de lá \\
\hline 09 & Incentivando a autoria por meio da escrita significativa \\
\hline 10 & Lendo, escrevendo e incluindo \\
\hline 11 & Escrever para ser lido \\
\hline 12 & Amigo secreto \\
\hline 13 & A metrópole no interior \\
\hline 14 & O interior na metrópole \\
\hline 15 & Conhecimento e aprendizado muito além de Português \\
\hline
\end{tabular}


No projeto de estágio, com relação à justificativa, os estagiários ressaltaram, sobretudo, o fato de que interlocutores reais tornariam a escrita significativa, além de explicitar o porquê da escolha desta modalidade:

Já que a interação é o objetivo primordial da linguagem, faz-se necessário resgatar a figura do interlocutor, fazendo o aluno assumir seu papel de sujeito na interação. A produção de cartas destinadas a colegas ainda não conhecidos torna isso possível, pois os alunos se dirigem a interlocutores reais, pessoas com expectativas e anseios que podem ser compartilhados. (Proj. 08)

O grande mérito do projeto CADIS é sua originalidade, tendo em vista o atual contexto crítico da educação no país. Optamos por fazer parte desse projeto, justamente pela possibilidade de "tentar algo novo" num conjunto desanimador de práticas repetitivas observadas durante nossa formação no decorrer do estágio do $1^{\circ}$ semestre. (Proj. 10)

No que tange aos objetivos, os autores dos projetos específicos focalizaram tanto o aluno como o professor, uma vez que o projeto permitia aos estagiários propiciar intervenção, mediando a formação contínua do professor:

A realização do CADIS em sala de aula tem como objetivo quebrar o ritmo das aulas de Português tradicionais, trazendo uma proposta em que o aluno poderá participar de uma atividade de leitura e escrita, agindo, portanto, como sujeito da interação. (...) Além de incentivar os jovens a perceberem o real uso da Língua Portuguesa, apresentamos novas possibilidades de trabalho para professores. (Proj. 10)

Em função das discussões na disciplina MELP sobre avaliação diagnóstica, tendo em vista a formação de grupos heterogêneos, a principal estratégia utilizada para a obtenção da produção escrita pelos alunos consistiu em propor a elaboração de uma carta de apresentação à(ao) estagiária(o):

Os grupos heterogêneos serão formados após a avaliação diagnóstica de cartas produzidas pelos alunos para a estagiária responsável. Após se apresentar e esperar que os alunos se apresentem, a estagiária entregará a cada aluno uma carta, com informações pessoais que façam com que os alunos se sintam à vontade para se apresentarem a ela também. A partir da carta-resposta, estagiárias e professoras avaliarão o desempenho dos 
Estágio supervisionado e práticas de oralidade, leitura e escrita no ensino fundamental

alunos para dividi-los em grupos. O auxílio da professora é indispensável, por conhecê-los há mais tempo e já ter tido contato com outras produções. (Proj. 05)

Como ponto de partida para a primeira interação entre os alunos, algumas duplas de estagiários deixaram os grupos mais livres, enquanto outras apresentaram sugestôes e/ou instruções:

Nosso objetivo na primeira intervenção, após a formação dos grupos heterogêneos, é fazer os alunos se apresentarem para as crianças da outra escola. Os grupos escreverão cartas descrevendo todos os componentes. Pretendemos deixá-los livres para escreverem as informações que julgarem necessárias. (Proj. 12)

$\mathrm{Na}$ nossa proposta para a primeira interação, os grupos deverão escrever uma carta, considerando as normas do gênero (data, remetente, destinatário etc.), na qual irão se apresentar (nome, idade etc.) e apresentar a escola (descrição do local, dos professores, do que mais gostam na escola, do que menos gostam na escola, qual a disciplina favorita, qual a disciplina de que não gostam etc). (Proj. 04)

Resultados: excertos dos relatórios de estágio apresentados em 2008

Ao ler os relatórios de estágios, pôde-se verificar que há fortes evidências de que o projeto CADIS despertou o interesse dos alunos e dos educadores:

Da sala dos professores, vinha uma excelente notícia: "Eles só falam no projeto. Anseiam por conhecer os novos amigos". Os alunos receberamme já organizados em grupo. (RE 01)

Com relação ao envolvimento com a modalidade escrita da língua, o projeto atingiu seu objetivo, como podemos observar pelos depoimentos que seguem:

O CADIs é uma grande oportunidade de envolver os alunos no processo de domínio da língua escrita, pois, a partir de uma situação real, os faz vivenciar a importância de saber escrever para se fazer entender. Eles se esforçam para escrever de modo claro e correto, refletem e discutem entre eles sobre aspectos gramaticais da língua. Essa preocupação se dá por saberem tratar-se de um interlocutor real e, além disso, um possível novo amigo, o que por si só já é bastante motivador nesta faixa etária. (RE 13) 
Por meio das observações já realizadas, vemos que os resultados obtidos a partir do desenvolvimento do projeto CADIs foram excelentes, no que tange ao desenvolvimento da linguagem e à ampliação do desejo de escrever e ler dos alunos. Em todas as aulas os discentes conversaram e houve barulho. Porém, entendemos aqui que o "barulho produtivo" é melhor que a passividade. (RE 08)

Tendo em vista a formação dos grupos heterogêneos, a partir da avaliação diagnóstica, surgiram dificuldades em organizar certos grupos, pois alguns alunos não desejavam trabalhar com outros:

Neste momento, conversei com os alunos para explicar a necessidade de trabalharem com seus colegas, conhecendo-os e aprendendo com as diferenças. Obviamente, não deixei claro para eles que as diferenças eram quanto à sua escrita. Depois de conversar com os alunos, foi possível separar os grupos e solicitar o início das cartas para os colegas. (RE 15)

Em vários relatórios, houve registro referente à participação de alunos com dificuldades de aprendizagem:

Além deste, outro objetivo do CADIS foi atingido: propor atividades que visem ao desenvolvimento da oralidade, da leitura e da produção escrita de forma prazerosa e, consequentemente, propiciar o avanço dos alunos com dificuldades de aprendizagem em leitura e escrita. Até mesmo a professora Ana ficou surpresa em ver que alguns alunos se sentiam extremamente motivados a escrever as cartas e até ficavam após o horário se dedicando a escrever um texto interessante. (RE 10)

Se, na maioria dos relatórios, a interação entre os grupos das duas escolas ocorreu de forma tranquila, houve também relatos sobre diferenças que conturbaram um pouco o relacionamento:

Ainda, os alunos escolhidos, apesar de pertencerem à mesma série, eram bem diferentes entre si. Os alunos da Deolinda se preocupavam com temas para a escrita e sempre queriam sugestôes para escrever. Por outro lado, os alunos da Godofredo se interessavam mais pela interação e reclamavam das cartas tão "certinhas" da escola da Deolinda. (RE 11) ficantes:

Vale ressaltar que alguns grupos chegaram a produtos finais grati-

A criação de narrativas para leitores reais, e não apenas para o professor avaliar, motivou-os a criar histórias muito interessantes. Embora tenham 
Estágio supervisionado e práticas de oralidade, leitura e escrita no ensino fundamental

tido pouco tempo para executar essa atividade, o resultado foi satisfatório para todos os grupos, tanto que as histórias se transformaram no livro $\mathrm{Pe}$ quenas histórias, que foi entregue aos grupos e às professoras. (RE 12)

Por meio dos relatórios, foi possível constatar que os estagiários tiveram a possibilidade de reavaliar representaçôes sobre professores, alunos e escola:

A partir destes estágios, foi possível adquirir um conhecimento mais profundo a respeito da sala de aula e desmistificar alguns julgamentos em torno da instituição e dos alunos. A experiência de estágio foi surpreendente, a vivência dentro da escola faz tornar possível a recuperação do prestígio do ensino, bem como do professor e do estudante. No início do estágio, havia uma grande preocupação em relação ao comportamento dos alunos ditos "impossíveis", ou mesmo dos professores indiferentes, atuando em salas superlotadas. Felizmente, foi possível reavaliar estes conceitos. (RE 03)

Na maioria dos relatórios, há menção à experiência "marcante" que o CADIS proporcionou aos estagiários:

E é por experiência própria que digo que o CADIS tem que continuar. Foi a experiência mais marcante em cinco anos de formação, a mais humana. Não esquecerei os momentos divididos com a turma. A despedida também me mostrou como minha presença foi marcante na formação dos alunos. Acredito que eles também não vão se esquecer da estagiária que chegou timidamente, dizendo que eles trocariam cartas com outras pessoas que eles nem conheciam. Apesar de parecer loucura, foi muito divertido. Os alunos aprenderam a suportar o trabalho em grupo, mesmo tendo colegas com quem não se davam bem em seu grupo. Aprenderam a negociar. Criaram laços com os colegas distantes. Não queriam se despedir. (RE 05)

E como avaliação final do percurso, pôde-se constatar que o projeto CADIS "funciona”, que é uma "prática escolar" que produz resultados significativos, viabilizando as atividades de oralidade, leitura e escrita nas aulas de língua materna:

Por tudo isso, podemos concluir que esta deve ser uma experiência a ser vivida, transmitida, disseminada como prática escolar. Estimula a criatividade de professores e alunos. Aumenta a participação e estímulo. O CADIs é uma atividade completa. (RE 05) 


\section{Uma retrospectiva: dez anos de projeto CADIS}

Participar do CADIS sempre foi considerado um enorme desafio pelos estagiários:

Os desafios embutidos no projeto são vários: despertar e manter o interesse dos alunos; fazer com que trabalhem em grupo, ajudando e respeitando os colegas; estimular a produção dos alunos que não se interessam pela escrita; deixar que os alunos trabalhem de forma independente, influenciando o menos possível no que fazem e fazer com que eles não se apoiem de maneira excessiva nas professoras e estagiárias. (Proj. 05)

No decorrer desses dez anos, a grande maioria dos projetos específicos apresentados chegou ao fim. O saldo é extremamente positivo. Os motivos para a interrupção de alguns projetos foram variados: um dos estagiários da dupla não pôde mais frequentar a disciplina; alunos do $6^{\circ}$ ano de uma escola particular não quiseram mais se corresponder com os alunos de uma escola pública, porque "as cartas deles estavam muito mal escritas"; a temática "nutrição", sugerida pelas estagiárias, causou problemas e desgaste entre os componentes dos grupos, logo na primeira carta.

Com relação à temática, em alguns projetos havia mudanças a cada troca, enquanto em outros permaneceu constante. São exemplos: Música, Amizade, Namoro na escola, Moda, Família, Poluição nas cidades, $\mathrm{O}$ celular dentro e fora da escola, entre outras.

Em um número considerável de projetos, houve planejamento e elaboração de pelo menos um produto: livro de contos, escrito em parceria pelos alunos de duas escolas; vários minidicionários, cujos verbetes foram distribuídos entre os participantes dos grupos; um conjunto artesanal de cartóes postais, com fotografias dos locais mais significativos para cada grupo.

Como ponto fundamental concernente à produção escrita, a troca de correspondências entre interlocutores reais e da mesma faixa etária deu ensejo ao interesse pela reescrita/reformulação/revisão dos textos. Havia colaboração de todos para "melhorar o texto" e solicitações de auxílio à estagiária e à professora, uma vez que os alunos queriam mostrar aos colegas que "sabiam escrever bem".

No final das interações, em geral, houve troca de fotos e as estagiárias forneceram o endereço das escolas e os e-mails dos alunos. Em 
Estágio supervisionado e práticas de oralidade, leitura e escrita no ensino fundamental

determinado ano, uma dupla de estagiárias promoveu um encontro entre os correspondentes de $8^{a}$ série, na Faculdade de Educação da USP.

Ao término do ano letivo, na disciplina MELP, há sempre espaçotempo para as duplas de estagiários apresentarem uma síntese do projeto aos colegas da Licenciatura.

É possível dizer também que o projeto CADIs tem contribuído para a formação contínua de professores de língua materna nas escolas, uma vez que o envolvimento deles foi intenso, com raras exceçôes. Muitos deles se dispuseram a receber novos estagiários no ano seguinte, pois pretendiam incluir o projeto em seu planejamento.

\section{Considerações finais}

Nossas pesquisas que privilegiam a interlocução/interação verbal pretendem abrir caminhos para novas investigaçōes referentes a saberes da área específica, sobre práticas educativas e provenientes de estágios, que poderão contribuir para a construção do "arcabouço" da formação do professor de língua materna em escolas e que propiciem a inclusão de todos os alunos (Nóvoa, 1992; Semeghini-Siqueira, 1998, 2006).

O desafio de viabilizar o intercâmbio entre universidade e escola, por meio do estágio supervisionado, desencadeou um processo de formação inicial e de formação contínua, propiciando o repensar de práticas pedagógicas, em especial, a avaliação diagnóstica que amplia a percepção, pelo professor, do que efetivamente sabem ou não sabem os seus alunos, tendo em vista a formação de grupos heterogêneos/complementares.

O projeto CADIS visou, sobretudo, criar um ambiente para que os alunos com dificuldades de aprendizagem fossem acolhidos e pudessem avançar no desenvolvimento de habilidades de leitura e escrita, com a colaboração dos colegas mais experientes e com a mediação do estagiário e do professor. Além do ambiente propício, foram desenvolvidas práticas de oralidade, leitura e escrita, alicerçadas nos pressupostos teóricos da concepção interacional e sócio-discursiva da linguagem, visando à interlocução com o outro, de modo que o aluno se perceba como protagonista do processo de construção do conhecimento. Tratase de um processo dialógico que se concebe na interlocução entre grupos de alunos, uma vez que produzem um texto "tecido por muitas 
vozes”. É a presença/existência do outro que possibilita a construção do sentido desses discursos nas interaçôes verbais: no próprio grupo e entre os grupos da mesma escola. Esse processo é também polifônico, pois todo discurso é atravessado pela fala do outro, pelos diferentes pontos de vista; nasce de um trabalho sobre outros discursos, ou seja, das correspondências, das cartas que circulavam entre os grupos.

A partir dos relatórios de estágio, é possível dizer que o projeto CADIS propicia o envolvimento dos alunos do ensino fundamental no processo de domínio da língua escrita. O fato de saberem tratar-se de um interlocutor real "os faz vivenciar a importância de saber escrever para se fazer entender", agindo como sujeitos da interação. Nesse contexto, ao surgir a necessidade de reescrita do texto, os alunos se dedicam com afinco, por se tratar de uma atividade significativa, realizada em condiçôes de produção específicas. O entusiasmo/interesse dos alunos pela correspondência, por meio da negociação com interlocutores reais, é a tônica dominante em todos os relatórios. Confirma-se, pois, a ocorrência de uma interação permeada pela ludicidade, que envolvia linguagem verbal e não verbal. Vale ressaltar, também, que a execução do projeto pôde alterar, de forma positiva, as representações que os estagiários detinham dos professores, dos alunos e da escola, uma vez que asseveram a validade do projeto CADIS para a formação de professores de língua materna.

O horizonte de reflexôes sobre as relações entre contexto social e desenvolvimento da linguagem amplia-se, nessas vivências, pois se concebem práticas de oralidade, leitura e escrita que produzem sentido tanto para os alunos, como para os professores. Se, para Nóvoa (1992, p. 37), "a formação está indissociavelmente ligada à 'produção de sentidos' sobre as vivências, sobre as experiências de vida”, é possível dizer que os estágios supervisionados dão uma nova dimensão ao discurso construído na universidade, aguçando a percepção de todos nós para as reais prioridades da escola.

Recebido em maio de 2009 e aprovado em março de 2010.

\section{Referências}

BAKHTIN, M. Marxismo e filosofia da linguagem. São Paulo: HUCITEC, 1981. 
Estágio supervisionado e práticas de oralidade, leitura e escrita no ensino fundamental

BAKHTIN, M. Estética da criação verbal. São Paulo: Martins Fontes, 1992.

BIARNES, J. Universalité, diversité et sujet dans l'espace pédagogique. Paris: L'Harmattan, 1999.

BRONCKART, J-P. Activité langagière, textes et discours: pour un interactionisme socio-discursif. Neuchâtel: Delachaux et Niestlé, 1997.

FREINET, C. L'éducation du travail. Neuchâtel: Delachaux et Niestlé, 1967.

LAHIRE, B. Tableaux de familles: heurs et malheurs scolaires en milieux populaires. Paris: Seuil; Gallimard, 1995

MACEDO, N.D.; SEMEGHINI-SIQUEIRA, I. Biblioteca públicalbiblioteca escolar de pais em desenvolvimento: diálogo entre bibliotecária e professora para reconstrução de significados com base no Manifesto da UnesCo. (Prefácio de Alfredo Bosi). São Paulo: CRB-8, 2000.

MEIRIEU, P. La pédagogie entre le dire et le faire. Paris: ESF, 1995.

NÓVOA, A. (Coord.). Os professores e sua formação. Lisboa: Dom Quixote; IIE, 1992.

SCHNEUWLY, B.; BRONCKART, J.P. (Org.). Vygotsky aujourd'hui. Paris: Delachaux et Niestlé, 1995.

SCHNEUWLY, B.; DOLZ, J. Os gêneros escolares: das práticas de linguagem aos objetos de ensino. In: Schneuwly, B.; Dolz, J. (Org.). Gêneros orais e escritos na escola. São Paulo: Mercado de Letras, 2004. p. 71-91.

SCHÖN, D. Formar professores como profissionais reflexivos. In: Nóvoa, A. (Coord.). Os professores e sua formação. Lisboa: Dom Quixote; IIE, 1992. p. 77-92.

SEMEGHINI-SIQUEIRA, I. Leitura: avaliação e multidisciplinaridade na formação do educador. In: SÃO PAULO. Secretaria da Educação. Coordenadoria de Estudos e Normas Pedagógicas. Escola em movimento. São Paulo: SEE/CENP, 1995. p. 162-191.

SEMEGHINI-SIQUEIRA, I. A escola inclusiva investe nas potencialidades do aluno: tópicos para a reflexão com a comunidade. In: BAUMEL, 
R.; Semeghini-Siqueira, I. (Org.). Integrar/incluir. São Paulo: feusp; CAPES, 1998. p. 13-32.

SEMEGHINI-SIQUEIRA, I. Práticas pedagógicas vivenciadas no passado, a formação docente e a atuação do professor de Língua Portuguesa concernente ao ensino fundamental. In: CONGRESSO LUSOBRASILEIRO DE HISTÓRIA DA EDUCAÇÃO: LEITURA E ESCRITA, 3., 2000, Lisboa. Anais... Lisboa: Universidade de Lisboa, 2000. p. 57-66.

SEMEGHINI-SIQUEIRA, I. Modos de ler textos informativos impressos/virtuais e questóes sobre memória: estratégias para alavancar a construção do conhecimento em diferentes disciplinas. In: REZENDE, N.; Riolfi, C.; Semeghini-Siqueira, I. (Org.). Linguagem e educação: implicações técnicas, éticas e estéticas. São Paulo: Humanitas, 2006. p. 169-203.

SEMEGHINI-SIQUEIRA, I. Investir antes de avaliar crianças. Jornal da USP, São Paulo, v. 23, n. 817, p. 12, 10-16 dez. 2007.

SMOLKA, A.L.B. A criança na fase inicial da escrita: a alfabetização como processo discursivo. São Paulo: Cortez; Campinas: Unicamp, 1988.

VIGOTSKI, L.S. A formação social da mente. São Paulo: Martins Fontes, 1984.

VIGOTSKI, L.S. Pensamento e linguagem. São Paulo: Martins Fontes, 1987.

WERTSCH, J.V.; SMOLKA, A.L.B. Continuando o diálogo: Vygotsky, Bakhtin e Lotman. In: Daniels, H. (Org.). Vygotsky em foco: pressupostos e desdobramentos. Campinas: Papirus, 1994. p. 121-150. 